\title{
An Intercomparison of Model-Predicted Wave Breaking for the 11 January 1972 Boulder Windstorm
}

\author{
J. D. Doyle, ${ }^{a}$ D. R. Durran, ${ }^{\mathrm{b}}$ C. Chen,,${ }^{\mathrm{c}}$ B. A. Colle, ${ }^{\mathrm{b}}$ M. Georgelin, ${ }^{\mathrm{d}}$ V. Grubisic, ${ }^{\mathrm{e}}$

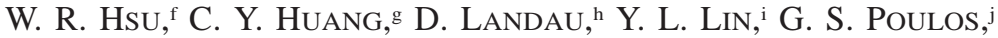 \\ W. Y. Sun, ${ }^{k}$ D. B. Weber, ${ }^{1}$ M. G. Wurtele, ${ }^{\text {h }}$ AND M. XuE ${ }^{1}$ \\ ${ }^{a}$ Naval Research Laboratory, Monterey, California \\ ${ }^{\mathrm{b}}$ University of Washington, Seattle, Washington \\ ${ }^{\circ}$ NASA GSFC, Greenbelt, Maryland \\ ${ }^{d}$ Laboratoire d'Aérologie, Université Paul Sabatier, Toulouse, France \\ ' National Center for Atmospheric Research, Boulder, Colorado \\ ${ }^{\mathrm{f}}$ National Taiwan University, Taipai, Taiwan \\ ${ }^{g}$ National Central University, Taipai, Taiwan \\ ${ }^{\mathrm{h}}$ University of California, Los Angeles, Los Angeles, California \\ ${ }^{\mathrm{i}}$ North Carolina State University, Raleigh, North Carolina \\ ${ }^{j}$ Colorado Research Association, Boulder, Colorado \\ ${ }^{\mathrm{k}}$ Purdue University, West Lafayette, Indiana \\ ${ }^{1}$ CAPS/University of Oklahoma, Norman, Oklahoma
}

11 December 1998 and 2 June 1999

\section{ABSTRACT}

\begin{abstract}
Two-dimensional simulations of the 11 January 1972 Boulder, Colorado, windstorm, obtained from 11 diverse nonhydrostatic models, are intercompared with special emphasis on the turbulent breakdown of topographically forced gravity waves, as part of the preparation for the Mesoscale Alpine Programme field phase. The sounding used to initialize the models is more representative of the actual lower stratosphere than those applied in previous simulations. Upper-level breaking is predicted by all models in comparable horizontal locations and vertical layers, which suggests that gravity wave breaking may be quite predictable in some circumstances. Characteristics of the breaking include the following: pronounced turbulence in the 13-16-km and 18-20-km layers positioned beneath a critical level near $21-\mathrm{km}$, a well-defined upstream tilt with height, and enhancement of upper-level breaking superpositioned above the low-level hydraulic jump. Sensitivity experiments indicate that the structure of the wave breaking was impacted by the numerical dissipation, numerical representation of the horizontal advection, and lateral boundary conditions. Small vertical wavelength variations in the shear and stability above $10 \mathrm{~km}$ contributed to significant changes in the structures associated with wave breaking. Simulation of this case is ideal for testing and evaluation of mesoscale numerical models and numerical algorithms because of the complex wave-breaking response.
\end{abstract}

\section{Introduction}

The basic theory for inviscid mountain waves forced by airflow over a two-dimensional obstacle in a stratified atmosphere has been established for several decades and has been the subject of several reviews (e.g., Queney et al. 1960; Smith 1979). As vertically propagating internal waves amplify, in part due to the decrease of atmospheric density with altitude and nonlinear processes, the mountain waves may overturn and lose energy due to turbulent breakdown. Although two- and three-dimensional models have been able to successfully

Corresponding author address: James D. Doyle, Naval Research Laboratory, Marine Meteorology Division, 7 Grace Hopper Avenue, Monterey, CA 93943-5502.

E-mail: doyle@nrlmry.navy.mil simulate gravity-wave generation (e.g., Smith 1979), evolution (e.g., Smith and Grønås 1993; Schär and Durran 1997), and breakdown (Clark and Peltier 1977; Bacmeister and Schoeberl 1989), numerous questions exist regarding the turbulent breakdown of three-dimensional gravity waves in nature. Furthermore, it has not been conclusively demonstrated that numerical models can accurately predict the occurrence of wave breaking over three-dimensional complex topography.

Mountain-wave breaking has an important influence on the atmosphere for several reasons. The vertical momentum flux associated with wave breaking and orographic drag has a profound impact on the atmospheric general circulation (Bretherton 1969) and requires careful representation in general circulation and numerical weather prediction models (Palmer et al. 1986; Lott 1995). Downslope windstorms and drag enhancement may occur as a result of resonant mountain-wave am- 
plification positioned beneath upper-level wave-breaking regions that contain "wave-induced" critical levels (Clark and Peltier 1977; Peltier and Clark 1979). Peltier and Clark (1979) attribute the windstorm formation to the bifurcation character of the flow response governed by the occurrence of breaking. Large vertical diffusivity associated with the turbulent breakdown of orographically generated gravity waves results in efficient vertical mixing of water vapor, aerosols, various chemical species, and trace gasses (Dörnbrack and Dürbeck 1998). Wave breaking represents an internal dissipation mechanism that leads to the generation of potential vorticity (Schär and Smith 1993) and subsequently may influence the downstream mesoscale and synoptic-scale flow (Thorpe et al. 1993; Aebischer and Schär 1998). Clearair turbulence in conjunction with the breakdown of gravity waves occurs frequently over complex terrain (Nastrom and Fritts 1992) and is a significant aviation hazard (Lilly 1978; Ralph et al. 1997).

One of the goals of the Mesoscale Alpine Programme (MAP) is to obtain a more complete understanding of the dynamics governing the turbulent breakdown of orographically generated gravity waves. MAP is a coordinated international effort to examine moist and dry processes associated with three-dimensional complextopographic flows including the physics and dynamics of heavy precipitation events, potential vorticity generation, gap flow, as well as gravity wave breaking (Binder and Schär 1996; Houze et al. 1998). High-resolution numerical simulations $(\Delta x \sim 3-6 \mathrm{~km}$ and $\sim 50$ vertical levels) were conducted on an operational basis during the MAP intensive observation periods in an attempt to predict the altitude and location of wave breaking regions over the Alps. The numerical forecasts were used as guidance for research aircraft missions designed to observe mountain wave breaking.

In preparation for the MAP field phase, a collaborative effort was established, as part of the pre-MAP research effort, to assess the ability of high-resolution numerical models to predict the location and strength of breaking waves in a series of experiments involving airflow over topography. The first test is a multimodel intercomparison of two-dimensional, high-resolution numerical simulations of the 11 January 1972 downslope windstorm that occurred along the Colorado Front Range. The dynamics of this windstorm has been the subject of numerous theoretical and numerical studies (e.g., Klemp and Lilly 1975; Clark and Peltier 1977; Klemp and Lilly 1978; Peltier and Clark 1979; Peltier and Clark 1983; Clark and Farley 1984; Durran 1986). The primary focus of this study is on the predictability and characteristics of the numerically simulated wave breaking rather than the dynamics of the leeside windstorm. Multiple regions of complex upper-level wave breaking develop in this case and represent a challenging test of the capability of various model architectures to produce equivalent wave-breaking simulations using identical initial conditions. The goal of this work is to examine the variability in the simulated gravity wave breaking among the 11 numerical models applied to this case rather than focusing on replication the finescale wind storm aspects. The distribution of the wave-breaking regions is particularly complex in the stratosphere, and it follows that one focus will be on the lower-stratospheric flow. In order to faithfully simulate the stratospheric response, the models were initialized using observations from the upstream sounding (Grand Junction, Colorado) through an altitude of $25 \mathrm{~km}$. As will be discussed, this initial sounding is much more representative of the actual lower stratospheric structure than those used in previous simulations of the 11 January 1972 windstorm.

\section{Experimental design and description of numerical models}

The configuration of the models is standardized as much as possible to facilitate a meaningful intercomparison. The models are applied in a two-dimensional mode with a horizontal grid increment of $1 \mathrm{~km}$ and a vertical grid spacing of $200 \mathrm{~m}$ up to an altitude of 25 $\mathrm{km}$ ( $\sim 125$ vertical levels). The mountain profile is a witch of Agnesi curve,

$$
z_{s}(x)=\frac{h a^{2}}{x^{2}+a^{2}},
$$

where $h$ is the mountain height and $a$ is the mountain half width. In these simulations, $a=10 \mathrm{~km}$ and $h=$ $2 \mathrm{~km}$, which are typical values for the Colorado Front Range. Although portions of the continental divide upstream of Boulder can be considered quasi-two-dimensional, the numerical models are applied in a two-dimensional mode in this study to facilitate simple and fundamental comparisons of the wave-breaking simulations. The horizontal boundaries are located $10 a(100$ $\mathrm{km})$ upstream and $12 a(120 \mathrm{~km})$ downstream of the mountain. Moist effects and rotation are not considered. A free-slip lower boundary condition is used. The model results are compared at the 3 -h time of a 4-h integration. The results at the 3 -h time are characterized by variations on slow timescales, with all models obtaining nominally equivalent predictions of the windstorm and upper-level wave breaking.

The initial conditions are horizontally homogeneous and based upon the upstream 1200 UTC 11 January 1972 Grand Junction, Colorado, sounding shown in Figs. 1a,b. The sounding contains multiple shear layers (Fig. 1a), strong low-level cross-mountain winds $(\sim 15$ $\left.\mathrm{m} \mathrm{s}^{-1}\right)$, and a well-defined stable layer above the mountain crest between $2 \mathrm{~km}$ and $7 \mathrm{~km}$ (Fig. 1b), with the latter two characteristics favorable for downslope windstorms (e.g., Brinkman 1974; Durran 1986). A critical level is present at $\sim 21 \mathrm{~km}$ where the cross-mountain wind speed is small. It is noteworthy that the wind and stability structure of the original sounding is retained up to $25 \mathrm{~km}$, in contrast to previous numerical studies 

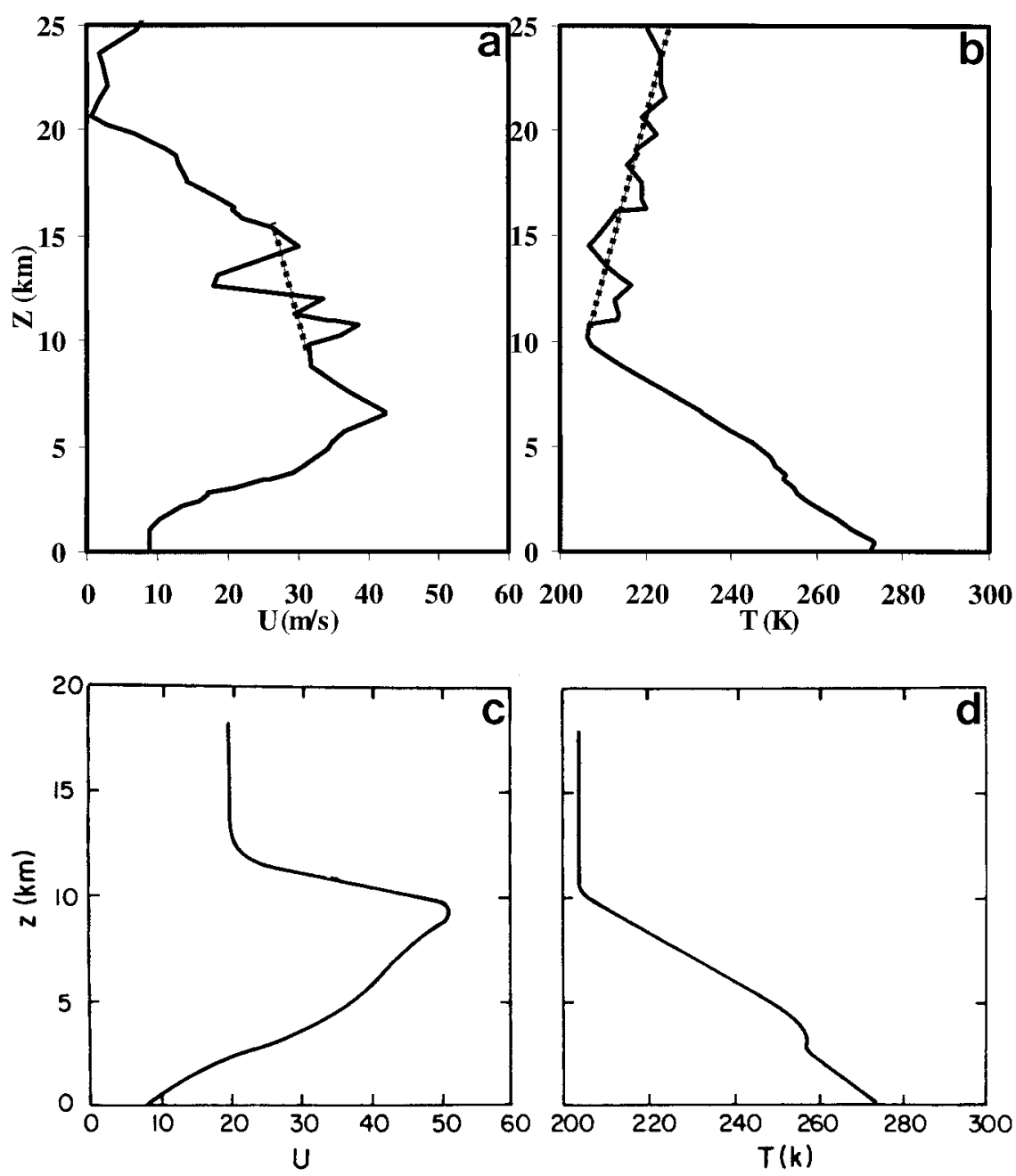

FIG. 1. Vertical profiles of the (a) $u$-component $\left(\mathrm{m} \mathrm{s}^{-1}\right)$ and (b) temperature (K) from the Grand Junction, CO, sounding for 1200 UTC 11 January 1972 (heavy solid line) and initial condition sensitivity experiment (dotted lines). Vertical profiles of the (c) $u$-component $\left(\mathrm{m} \mathrm{s}^{-1}\right)$ and (d) temperature (K) used in previous simulations of the 1200 UTC 11 January 1972 windstorm (after Peltier and Clark 1979).

that typically used smoothed profiles in the stratosphere (e.g., Peltier and Clark 1979), as shown in Figs. 1c,d. The initial sounding applied in the present study contains a more representative initial state in the stratosphere than used in previous simulations of the 11 January 1972 windstorm, which should presumably lead to a more realistic simulation of upper-level wave breaking.

The 11 January 1972 windstorm along the Colorado Front Range has been analyzed on numerous occasions both observationally (Lilly and Zipser 1972; Lilly 1978) and numerically (beginning with Klemp and Lilly 1975; Klemp and Lilly 1978; Peltier and Clark 1979) because of the rare direct in situ measurements of the mountain wave structure. The composite analyses of potential temperature and westerly wind component obtained from Sabreliner and Queen-Air aircraft flight data for this situation are shown in Fig. 2 (Klemp and Lilly
1975). A large-amplitude wave extends over $300 \mathrm{hPa}$ in the upper troposphere (Fig. 2a) and is nearly coincident with a deep layer of weak or near-reversed crossmountain flow (Fig. 2b), which is likely a manifestation of mountain-wave amplification and breaking. Lilly (1978) surmises that the $60 \mathrm{~m} \mathrm{~s}^{-1}$ downslope winds in the lee are consistent with a deep layer between 200 and $700 \mathrm{hPa}$ upstream of the mountains passing through a 260-hPa layer immediately above the surface in the lee of the mountain crest.

The numerical model characteristics and architectures applied in this study vary considerably, as summarized in Table 1. The models used in the intercomparison include the following: the Advanced Regional Prediction System (ARPS) (Xue et al. 1995), Coupled Ocean/ Atmosphere Mesoscale Prediction System (COAMPS) (Hodur 1997), Durran and Klemp (1983) model (DK83), Eulerian/semi-Lagrangian model (EULAG) (Smolarkie- 

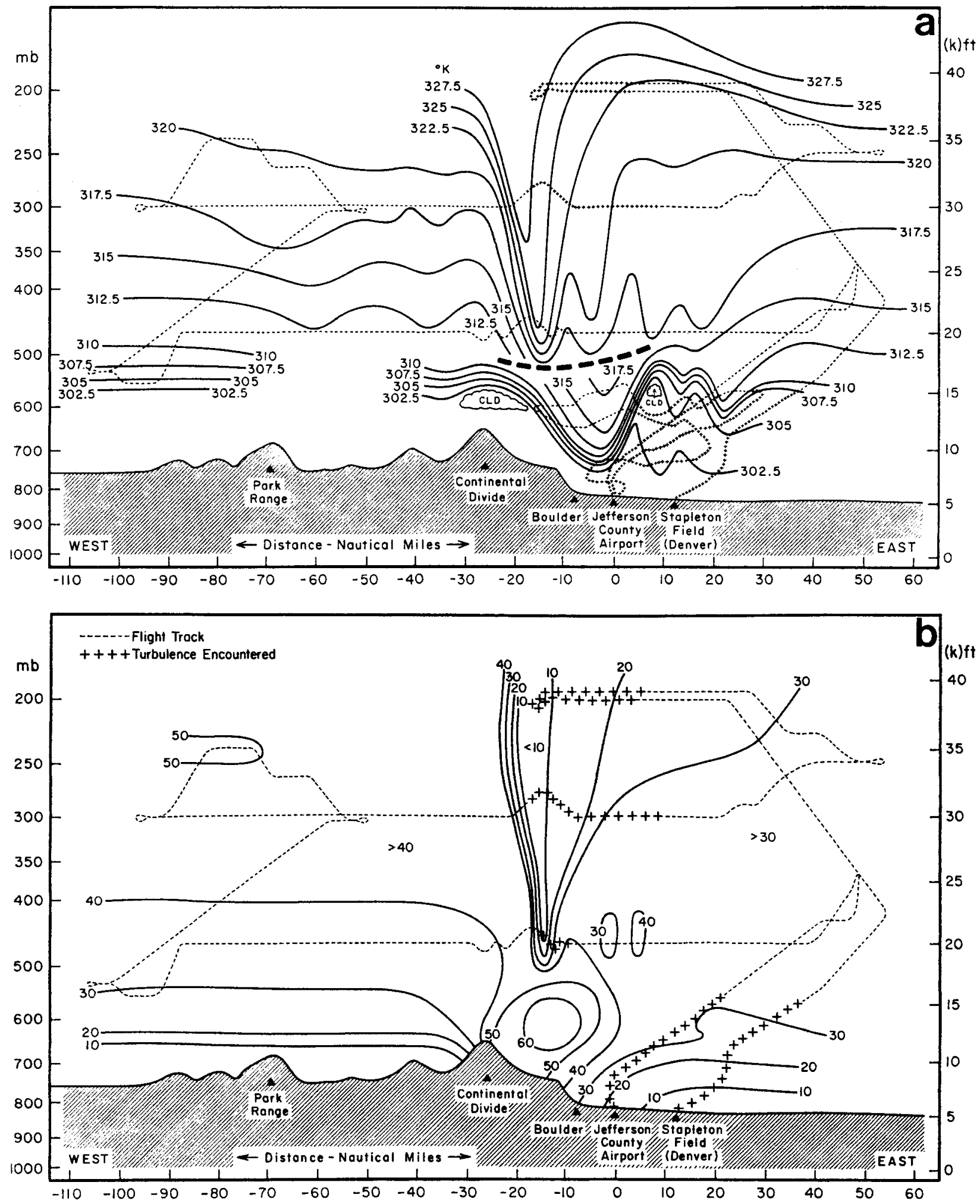

FIG. 2. Analysis of (a) potential temperature and (b) $u$-component speed from aircraft flight data and sondes taken on 11 January 1972. Aircraft tracks are shown by dashed lines with locations of significant turbulence shown by the plus signs. The heavy dashed line separates data taken by the Queen Air (before 2200 UTC) from the Saberliner data (after 0000 UTC) (from Klemp and Lilly 1975). 
TABLE 1. Model formulation and numerical characteristics. The model equations sets are delineated either as compressible (C), anelastic (A), or Arakawa Jacobian (A-J). The finite difference algorithms are referred to as centered in time (CIT), forward in time (FIT), centered in space (CIS), upstream in space (UIS), and semi-Lagrangian (SL).

\begin{tabular}{|c|c|c|c|c|c|c|c|c|c|}
\hline Model & $\begin{array}{l}\text { Eqn. } \\
\text { set }\end{array}$ & $\begin{array}{l}\text { Vert. } \\
\text { coord. }\end{array}$ & $\begin{array}{l}\text { Time } \\
\text { differ. }\end{array}$ & $\begin{array}{l}\text { Time step/ } \\
\text { filter } \\
\text { coef. }(\gamma)\end{array}$ & $\begin{array}{l}\text { Horizon. } \\
\text { advect. }\end{array}$ & $\begin{array}{l}\text { Horizon. } \\
\text { smooth/ } \\
\mathrm{K}_{\mathrm{D}}\end{array}$ & $\begin{array}{l}\text { Top } \\
\text { bound. } \\
\text { cond. }\end{array}$ & Initial. & $\begin{array}{l}\text { Turb. } \\
\text { param. }\end{array}$ \\
\hline ARPS & $\mathrm{C}$ & $\sigma_{z}$ & $\begin{array}{l}\text { CIT } \\
\text { Semi-implicit }\end{array}$ & $\begin{array}{l}\text { Large: } 9 \mathrm{~s} \\
\text { Small: } 1 \mathrm{~s} \\
\gamma=0.05\end{array}$ & $\begin{array}{l}\text { 4th Order } \\
\text { CIS }\end{array}$ & $\begin{array}{l}\text { 4th Order } \\
1.1 \times 10^{8} \mathrm{~m}^{4} \mathrm{~s}^{-1}\end{array}$ & Sponge & & $\begin{array}{l}1.5 \text { Order } \\
\text { (TKE) }\end{array}$ \\
\hline COAMPS & $\mathrm{C}$ & $\sigma_{z}$ & $\begin{array}{l}\text { CIT } \\
\text { Semi-implicit }\end{array}$ & $\begin{array}{l}\text { Large: } 3 \mathrm{~s} \\
\text { Small: } 1.5 \mathrm{~s} \\
\gamma=0.2\end{array}$ & $\begin{array}{l}\text { 2d Order } \\
\text { CIS }\end{array}$ & $\begin{array}{l}\text { 4th Order } \\
1.3 \times 10^{9} \mathrm{~m}^{4} \mathrm{~s}^{-1}\end{array}$ & Sponge & $\begin{array}{l}\mathrm{g}, \mathrm{U} \\
\text { Spin Up }\end{array}$ & $\begin{array}{l}1.5 \text { Order } \\
\text { (TKE) }\end{array}$ \\
\hline CUMM & A & $\sigma_{z}$ & FIT & $\begin{array}{l}\text { Large: } 1 \mathrm{~s} \\
\text { Small: N/A } \\
\text { N/A }\end{array}$ & $\begin{array}{l}\text { 7th Order } \\
\text { SL }\end{array}$ & $\begin{array}{l}\text { Implicit/ } \\
\text { Shapiro } \\
\text { Filter }\end{array}$ & Sponge & & $\begin{array}{l}1.5 \text { Order } \\
\text { (TKE) }\end{array}$ \\
\hline DK83 & $\mathrm{C}$ & $\sigma_{z}$ & $\begin{array}{l}\text { CIT } \\
\text { Simi-implicit }\end{array}$ & $\begin{array}{l}\text { Large: } 12 \mathrm{~s} \\
\text { Small: } 3 \mathrm{~s} \\
\gamma=0.2\end{array}$ & $\begin{array}{l}\text { 4th Order } \\
\text { CIS }\end{array}$ & $\begin{array}{l}\text { 4th Order } \\
1.3 \times 10^{9} \mathrm{~m}^{4} \mathrm{~s}^{-1}\end{array}$ & Radiative & $\begin{array}{l}\text { g, U } \\
\text { Spin Up }\end{array}$ & 1st Order \\
\hline EULAG & A & $\sigma_{z}$ & FIT & $\begin{array}{l}\text { Large: } 5 \mathrm{~s} \\
\text { Small: N/A } \\
\text { N/A }\end{array}$ & $\begin{array}{l}\text { 2d Order } \\
\text { UIS }\end{array}$ & $\begin{array}{l}\text { Implicit } / 2 \mathrm{~d} \\
\text { Order } \\
8 \mathrm{~m}^{2} \mathrm{~s}^{-1}\end{array}$ & Sponge & $\begin{array}{l}\text { Potential } \\
\text { flow } \\
(2 \mathrm{D})\end{array}$ & $\begin{array}{l}\text { 1.5 Order } \\
\text { (TKE) }\end{array}$ \\
\hline MESO-NH & A & $\sigma_{z}$ & CIT & $\begin{array}{l}\text { Large: } 8 \mathrm{~s} \\
\text { Small: N/A } \\
\gamma=0.2\end{array}$ & $\begin{array}{l}\text { 2d Order } \\
\text { CIS }\end{array}$ & $\begin{array}{l}\text { 4th Order } \\
4.1 \times 10^{8} \mathrm{~m}^{4} \mathrm{~s}^{-1}\end{array}$ & Sponge & & $\begin{array}{l}1.5 \text { Order } \\
\text { (TKE) }\end{array}$ \\
\hline MM5 & $\mathrm{C}$ & $\sigma_{z}$ & $\begin{array}{l}\text { CIT } \\
\text { Semi-implicit }\end{array}$ & $\begin{array}{l}\text { Large: } 3 \mathrm{~s} \\
\text { Small: } 1 \mathrm{~s} \\
\gamma=0.1\end{array}$ & $\begin{array}{l}\text { 2d Order } \\
\text { CIS }\end{array}$ & $\begin{array}{l}\text { 4th Order } \\
1.0 \times 10^{9} \mathrm{~m}^{4} \mathrm{~s}^{-1}\end{array}$ & Radiative & & 1st Order \\
\hline NTU/Purdue & $\mathrm{C}$ & $\sigma_{z}$ & $\begin{array}{l}2 \text { Step } \\
\text { Forward-Backward }\end{array}$ & $\begin{array}{l}\text { Large: } 1 \mathrm{~s} \\
\text { Small: } 0.3 \mathrm{~s} \\
\text { N/A }\end{array}$ & $\begin{array}{l}\text { 2d Order } \\
\text { CIS }\end{array}$ & $\begin{array}{l}2 \mathrm{~d} \text { Order } \\
1.3 \times 10^{4} \mathrm{~m}^{2} \mathrm{~s}^{-1}\end{array}$ & Sponge & $\begin{array}{l}\text { g, U } \\
\text { Spin Up }\end{array}$ & 1st Order \\
\hline RAMS & $\mathrm{C}$ & $\sigma_{z}$ & $\begin{array}{l}\text { CIT } \\
\text { Semi-implicit }\end{array}$ & $\begin{array}{l}\text { Large: } 3 \mathrm{~s} \\
\text { Small: } 1 \mathrm{~s} \\
\gamma=0.2\end{array}$ & $\begin{array}{l}\text { 2d Order } \\
\text { CIS }\end{array}$ & 4th Order & Sponge & $\begin{array}{l}\text { U } \\
\text { Spin Up }\end{array}$ & $\begin{array}{l}1.5 \text { Order } \\
\text { (TKE) }\end{array}$ \\
\hline RIMS & $\mathrm{C}$ & $\sigma_{z}$ & $\begin{array}{l}\text { Adams-Bash: } \\
\text { Semi-implicit }\end{array}$ & $\begin{array}{l}\text { Large: } 1 \mathrm{~s} \\
\text { Small: } 0.2 \mathrm{~s} \\
\gamma=\text { N/A }\end{array}$ & $\begin{array}{l}\text { 4th Order } \\
\text { CIS }\end{array}$ & $\begin{array}{l}\text { 4th Order } \\
5.0 \times 10^{9} \mathrm{~m}^{4} \mathrm{~s}^{-1}\end{array}$ & Sponge & & 1st Order \\
\hline UCLA & A-J & step & CIT & $\begin{array}{l}\text { Large: } 3 \mathrm{~s} \\
\text { Small: N/A } \\
\gamma=\text { N/A }\end{array}$ & $\begin{array}{l}\text { 2d Order } \\
\text { CIS }\end{array}$ & None & Sponge & & None \\
\hline
\end{tabular}

wicz and Margolin 1997), the Central University Mesoscale Model (CUMM) (Huang 2000), MesoscaleNonhydrostatic (MESO-NH) Model (Lafore et al. 1998), Penn State-NCAR Mesoscale Model (MM5) (Dudhia 1993), National Taiwan University (NTU)/Purdue Model (Hsu and Sun 1999, manuscript submitted to Mon. Wea. Rev.), Regional Atmospheric Modeling System (RAMS) (Pielke et al. 1992), Regional Integrated Modeling System (RIMS) (Chen 1991), and the UCLA model (Landau et al. 1997). All of the models applied in this study are nonhydrostatic with several making use of the anelastic equation set (EULAG, CUMM, MESO-NH), others solving the fully compressible equations (ARPS, COAMPS, DK83, MM5, NTU/Purdue, RAMS, RIMS) and one model applying the Arakawa Jacobian method to predict the streamfunction and vorticity (UCLA). The vertical coordinates are terrain following $\left(\sigma_{z}\right)$ with the exception of the UCLA model, which uses a block-type coordinate system. The models differ significantly in spatial and temporal finite differencing techniques. For example, a group of models (COAMPS, MM5, RAMS) make use of standard formulations such as second-order accurate centered temporal and spatial differencing, in contrast to other models that use forward-temporal and upstream-spatial differencing (EULAG) or centered temporal and higher-order accurate spatial differencing (ARPS, CUMM, DK83). Significant differences among models exist in the magnitude of the horizontal smoothing and time filter coefficients. Additionally, some models employ second-order horizontal smoothing (EULAG, NTU/Purdue) while others use fourth-order smoothing. Turbulence is represented by simple firstorder closure techniques in several models (DK83, MM5, RIMS, NTU/Purdue). In contrast, an explicit predictive equation for turbulent kinetic energy is employed by a number of models (ARPS, COAMPS, CUMM, EULAG, MESO-NH, RAMS) to parameterize the subgridscale vertical transport. It is noteworthy that the UCLA model does not parameterize the subgridscale turbulence and relies on the gridscale diffusive processes for vertical diffusion and mixing. Several models use a spinup period for the $u$-component and/or gravity (COAMPS, DK83, NTU/Purdue, RAMS), while EULAG uses a two-dimensional potential flow initialization. The UCLA model makes use of cyclic lateral 
boundary conditions in contrast to the other models, which use radiative boundary conditions.

\section{Results}

\section{a. Control simulations}

The simulated potential temperature after $3 \mathrm{~h}$ for the 11 models is shown in Fig. 3. All of the models produce two deep regions of wave breaking located in the stratosphere, near $\sim 13-16 \mathrm{~km}$ and $\sim 18-20 \mathrm{~km}$, with a vertical wavelength of $\sim 3-4 \mathrm{~km}$ and an upstream vertical tilt. The UCLA model results (Fig. 3k) differ from the other simulations in that the stratospheric wave-breaking regions are less coherent, with numerous small-scale superadiabatic regions, particularly in the troposphere (some filtering has been applied to the UCLA model output). The lack of a subgridscale eddy viscosity parameterization may lead to greater high-frequency structures in the UCLA model relative to the other simulations, which make use of subgridscale turbulence schemes (Table 1).

All 11 of the models produce a significant leeside windstorm, as indicated in Fig. 4. The lee-slope wind maximum at the 3-h time varies considerably from $\sim 86$ $\mathrm{m} \mathrm{s}^{-1}$ for RIMS to $\sim 43 \mathrm{~m} \mathrm{~s}^{-1}$ for the UCLA model. This variability in the model simulations may be a reflection of differences in model formulation as well as the unsteady character of the wave breaking. Significant differences among the model simulations exist in the flow upstream of the barrier near the $7 \mathrm{~km}$ altitude, ranging from $\sim 43 \mathrm{~m} \mathrm{~s}^{-1}$ for the MM5 results to greater than $52 \mathrm{~m} \mathrm{~s}^{-1}$ for CUMM. A well-defined hydraulic jump, as evidenced in the potential temperature and velocity fields, is positioned along the lee slope in several model simulations (e.g., DK83, EULAG) and 10-25 km downstream in other simulations (CUMM, RAMS, RIMS). Substantial variations exist in the movement of the jump and the transition to the ambient downstream conditions. These differences are consistent with the large model variability (factor of 2) in maximum vertical velocity near the hydraulic jump at the 3-h time. Variations in the hydraulic jump behavior and characteristics are likely influenced by lateral boundary formulation and the unsteady nature of the solution.

The model simulations reproduced the characteristics of the tropospheric structure analyzed by Klemp and Lilly (1975) and Lilly (1978) (Fig. 2) reasonably well, such as the wind speed maximum in the lee, the hydraulic jump, the midtropospheric cross-mountain wind component minimum in the lee, and the weak stability layer associated with the midlevel gravity wave steepening and breaking. However, Klemp and Lilly's analysis does not support the model simulated downward tropopause depression associated with breaking superpositioned over the low-level hydraulic jump. The hydraulic jump extends to a greater altitude and has a steeper slope in nearly all of the simulations than indicated by the aircraft observations. Some of these differences may be related to the simplicity of model architectures, including the two-dimensional and inviscid configuration, as well as the simplified model initial state and topography representation.

The upper-level wave breaking is apparent in the Richardson number $\left(R_{i}\right)$ fields in Fig. $5\left[\operatorname{sgn}\left(R_{i}\right)\left|R_{i}\right|^{0.5}\right.$ was chosen for graphical purposes]. The upper-level breaking regions in several of the model simulations extend to $\sim 10 a$ downstream and $\sim 2 a$ upstream of the mountain. In all of the simulations, with the exception of the UCLA model, the largest amplitude breaking, as measured by the vertical excursion of the isentropes (Fig. 3), is located just downstream and above the lowertropospheric hydraulic jump. Regions of small $R_{i}$ can be found in the lower troposphere in the vicinity of the hydraulic jump and above the lee slopes in a nearly adiabatic layer between 6 and $8 \mathrm{~km}$ (Fig. 3). This layer is characterized by flow stagnation, with some models containing a deep region of reversed flow (Fig. 4). The damping effect of the critical layer, which limits the vertical extent of the breaking, is apparent in the $R_{i}$ (Fig. 5) and potential temperature fields (Fig. 3). In spite of significant differences between the models in the lowlevel hydraulic structures, vertical velocities, and leeside winds, the vertical and horizontal locations of the wave breaking are generally similar in all model simulations. The UCLA model, which produced breaking structures in similar layers as the other models, however, differed substantially in terms of the vertical coherence and highfrequency waves. Some of the differences between model simulations may arise due to the transient nature of the wave breaking, which makes comparison at a particular time difficult. Even though a complete steady state is generally not achievable in these simulations, comparison of the model solutions at a given time is still meaningful, especially with regard to predictability issues.

Although there are many broad similarities in the overall structure of the wave breaking in nearly all of the simulations, some noteworthy differences in the upper-level breaking structures exist. For example, several model simulations contain breaking regions in the lower stratosphere downstream of the mountain that penetrate downward below $7 \mathrm{~km}$ resulting in a deep adiabatic layer (Figs. 3a and 3j). Additionally, these two simulations contain more small-scale structures associated with the wave breaking, which may be due to the strength of the numerical smoothing. A number of model simulations contain trapped waves downstream of the wave breaking in the 10-14 km layer (Figs. 3e, 3g, 3h, and $3 \mathrm{i}$ ). Some of the differences between model solutions may be related to the relative strength of the explicit or implicit numerical smoothing (Table 1). Some models that used smaller horizontal smoothing eddy diffusivity $\left(K_{D}\right)$ and Robert (1966)/Asselin (1972) time filter $(\gamma)$ coefficients tend to contain smaller-scale wave 


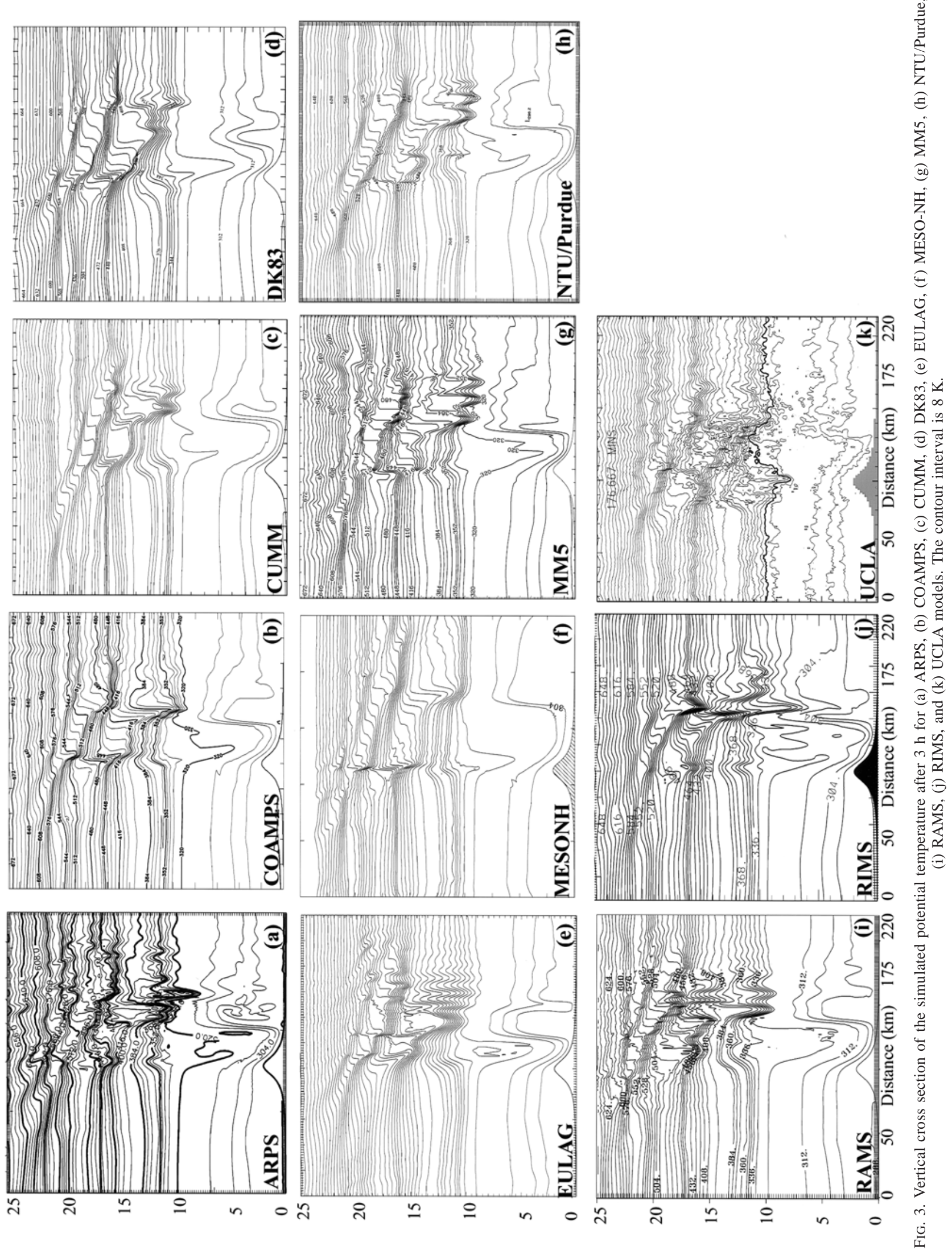



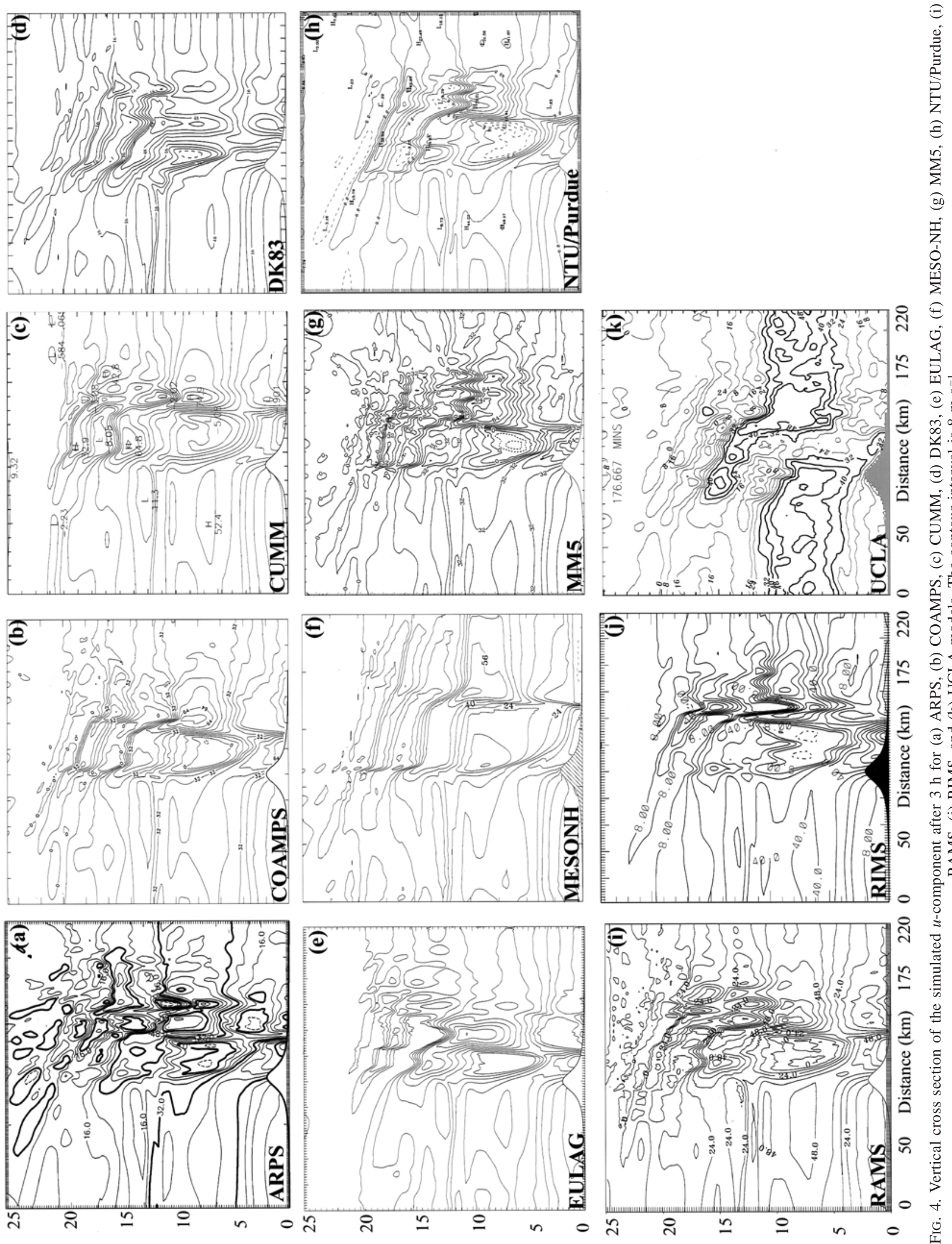

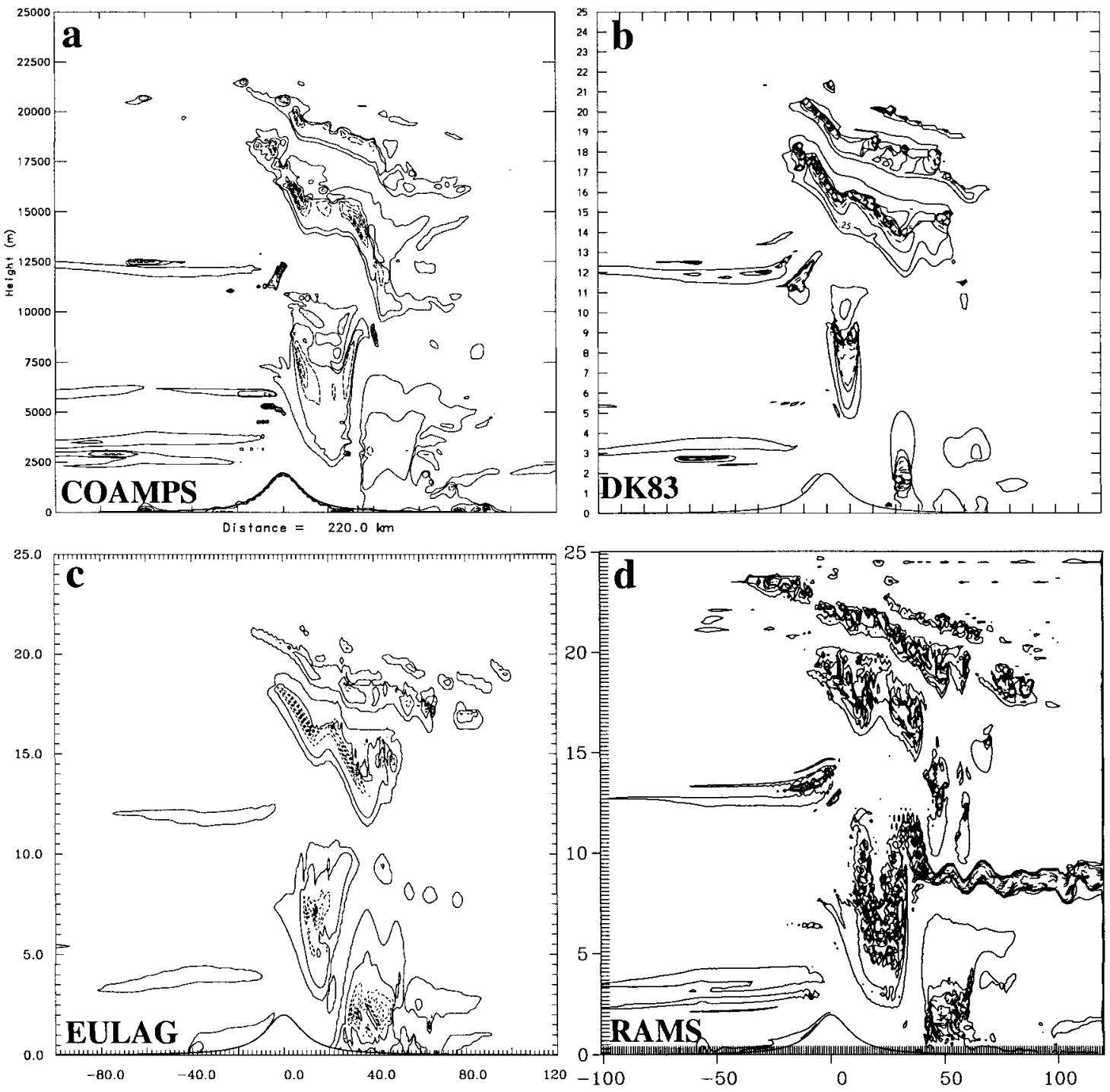

FIG. 5. The $\operatorname{sgn}\left(R_{i}\right)\left|R_{i}\right|^{0.5}$ for the 3-h time for (a) COAMPS, (b) DK83 model, (c) EULAG, and (d) RAMS. The isopleths between 1.0 and -5 are displayed every 0.5 .

breaking substructures relative to the other models that apply a larger $K_{D}$ and/or $\gamma$ (see Figs. 3, 4). However, there are notable exceptions to this relationship clearly suggesting aspects of the model formulation other than horizontal smoothing likely control the simulation of finescale breaking signatures. For example, RIMS (Figs. $3 \mathrm{j}$ and $4 \mathrm{j}$ ), which used a relatively large $K_{D}$, qualitatively produces higher amplitude small-wavelength structures than MESO-NH (Figs. 3f and 4f), which makes use of a relative small $K_{D}$.

\section{b. Sensitivity tests}

Experiments were performed to isolate the sensitivity of the wave breaking to the dissipation, advection scheme, and lateral boundary conditions. The 3-h potential temperature field, obtained using COAMPS with second-order horizontal smoothing, is shown in Fig. 6a. In comparison with the control simulation (Fig. 3b), which made use of a more scale-selective fourth-order horizontal smoothing, not surprisingly the increased dissipation leads to shallower neutral layers downstream of the major wave-breaking source regions. The vertical excursion of the isentropes downstream of the hydraulic jump is reduced as well. Moreover, the sensitivity of these breaking structures to the horizontal smoothing or diffusion is illustrated by the ARPS results in Fig. 6b, which is a simulation that made use of a fourth-order horizontal smoothing coefficient that was doubled relative to the control simulation (Fig. 3a). As expected, the increase in the horizontal smoothing results in a decrease of the small-scale structure associated with the breaking and a decrease in the amplitude of the breaking positioned above the hydraulic jump. An increase in the 

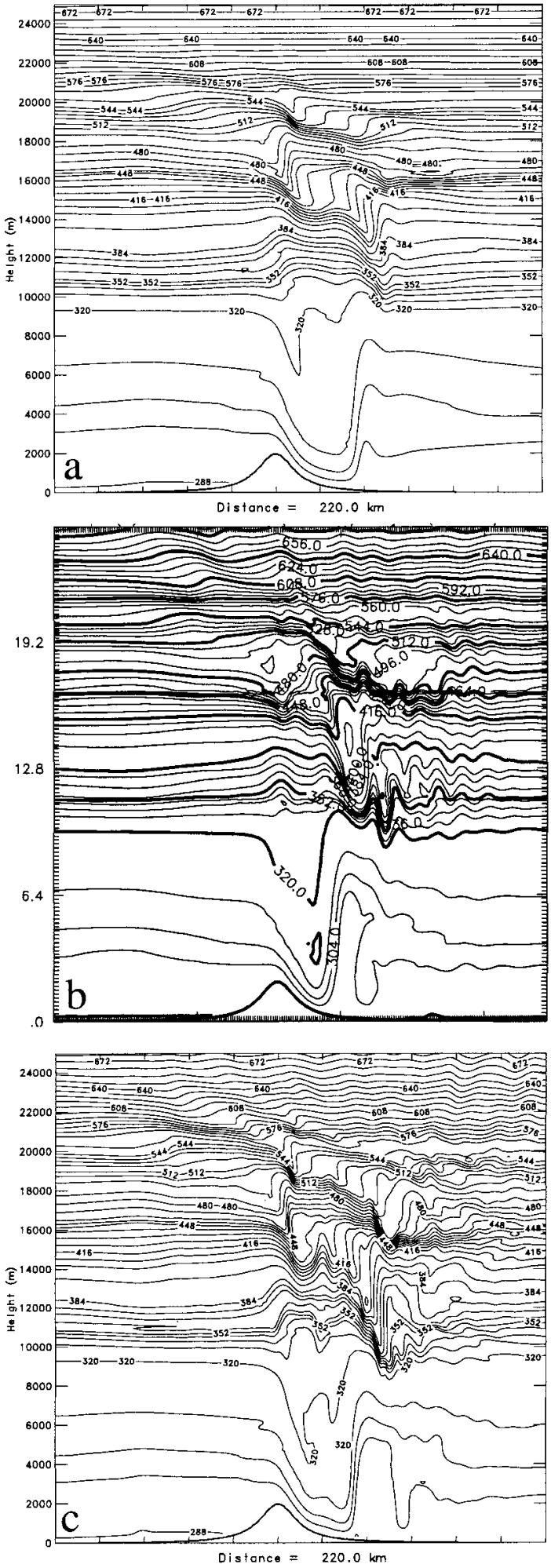

FIG. 6. The 3-h potential temperature for (a) COAMPS with secondorder horizontal smoothing, (b) ARPS with fourth-order horizontal smoothing coefficient doubled relative to the control, and (c) COAMPS with fourth-order accurate horizontal advection. The contour interval is $8 \mathrm{~K}$.
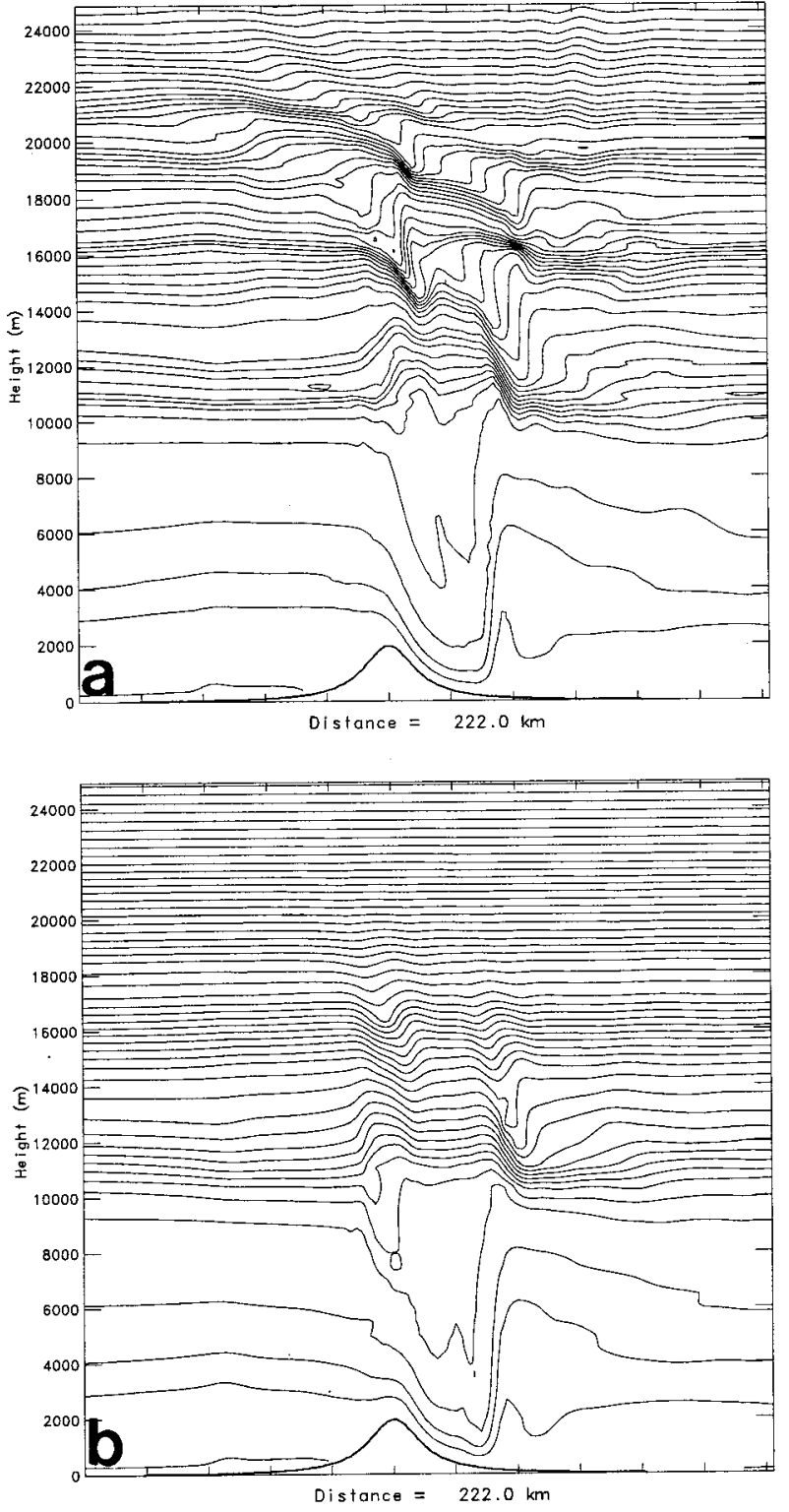

FIG. 7. The 3-h potential temperature for COAMPS using (a) $\Delta x$ $=2 \mathrm{~km}$ and 125 vertical levels and (b) $\Delta x=2 \mathrm{~km}$ and 45 vertical levels. The contour interval is $8 \mathrm{~K}$.

accuracy of the horizontal-spatial advection from second-order (Fig. 3b) to fourth-order (Fig. 6c) increases the small-scale wave activity associated with wave breaking. However, the fundamental amplitude and vertical wavelength of the wave breaking regions are similar and appear to be independent of finite-difference technique. Additional experiments indicate a sensitivity of the hydraulic jump location and structure to the lateral boundary condition formulation (not shown).

Several experiments were conducted with degraded horizontal and vertical resolution. A COAMPS simulation with $\Delta x=2 \mathrm{~km}$, shown in Fig. 7a, indicates relative insensitivity to a doubling of the horizontal grid 
increment. Relative to the control (Fig. 3b), notable degradation of the gravity wave related structures exists near the hydraulic jump and in the upper-level gravity wave breaking due to the coarser resolution. The 3-h potential temperature obtained from a COAMPS simulation using a vertically staggered grid with 45 levels and $\Delta x=2 \mathrm{~km}$ is shown in Fig. $7 \mathrm{~b}$. The vertical grid spacing is based on what a typical high-resolution operational model might use. The resolution in the lower stratosphere, $\Delta z=700 \mathrm{~m}$, is clearly insufficient to resolve the wavebreaking structures relative to the control simulation (Fig. 7a), especially considering the vertical wavelength is $\sim 3-4 \mathrm{~km}$. Clearly, some caution should be exercised when choosing the vertical grid configuration for numerical models used to predict the occurrence of wave breaking and clear-air turbulence.

The sensitivity of orographically generated wave breaking to the initial state was tested by performing two simulations. The original Grand Junction sounding (Fig. 1) contains small vertical wavelength $u, t$, and $R_{i}$ structures in the lower stratosphere that may have an important influence on the upper-level wave breaking. To examine the relevance of these vertical structures, the first experiment makes use of smoothed stratospheric velocity and thermal profiles (dotted lines in Figs. 1a,b). The profiles are modified such that the layer-mean zonal momentum and vertical thermal gradient are preserved from the original sounding. The 3-h potential temperature field using COAMPS (Fig. 8a) indicates that the vertical wavelength of the upper-level wave breaking $(\sim 3 \mathrm{~km})$ and the lowest altitude of wave breaking over the mountain peak and lee slope are similar in both the modified initial condition and control simulations (Fig. $3 b)$. However, there are significant differences apparent in the local wave-breaking regions in the stratosphere. For example, in the 10-15 km layer, $40 \mathrm{~km}$ downstream of the mountain peak, the wave breaking is much more vigorous and extends to a lower altitude in the control than the simulations that used smoothed profiles. The gravity wave-breaking response is spatially more extensive in the simulation that used smoothed profiles, particularly in the upstream. Additionally, the maximum leeside winds at $3 \mathrm{~h}$ are $\sim 32 \mathrm{~m} \mathrm{~s}^{-1}$ using the smoothed sounding, while in the control experiment has a $65 \mathrm{~m}$ $\mathrm{s}^{-1}$ maximum. Overall, the fundamental character of the stratospheric breaking is similar, however, the finescale structure of the wave breaking including the horizontal and vertical position and magnitude of local $R_{i}$ minima appear to be sensitive to initial condition variations in the stratosphere. This result is in agreement with Blumen (1988), who examined Long's solution for a nonlinear hydrostatic wave with periodic upstream flow and found that the basic processes of wave breaking were unaffected. However, the level at which breaking first occurs and the wave displacement were altered by the nonuniform upstream flow. Thus, the relatively coarse vertical resolution commonly used in both analysis and model systems in the stratosphere may limit the pre-
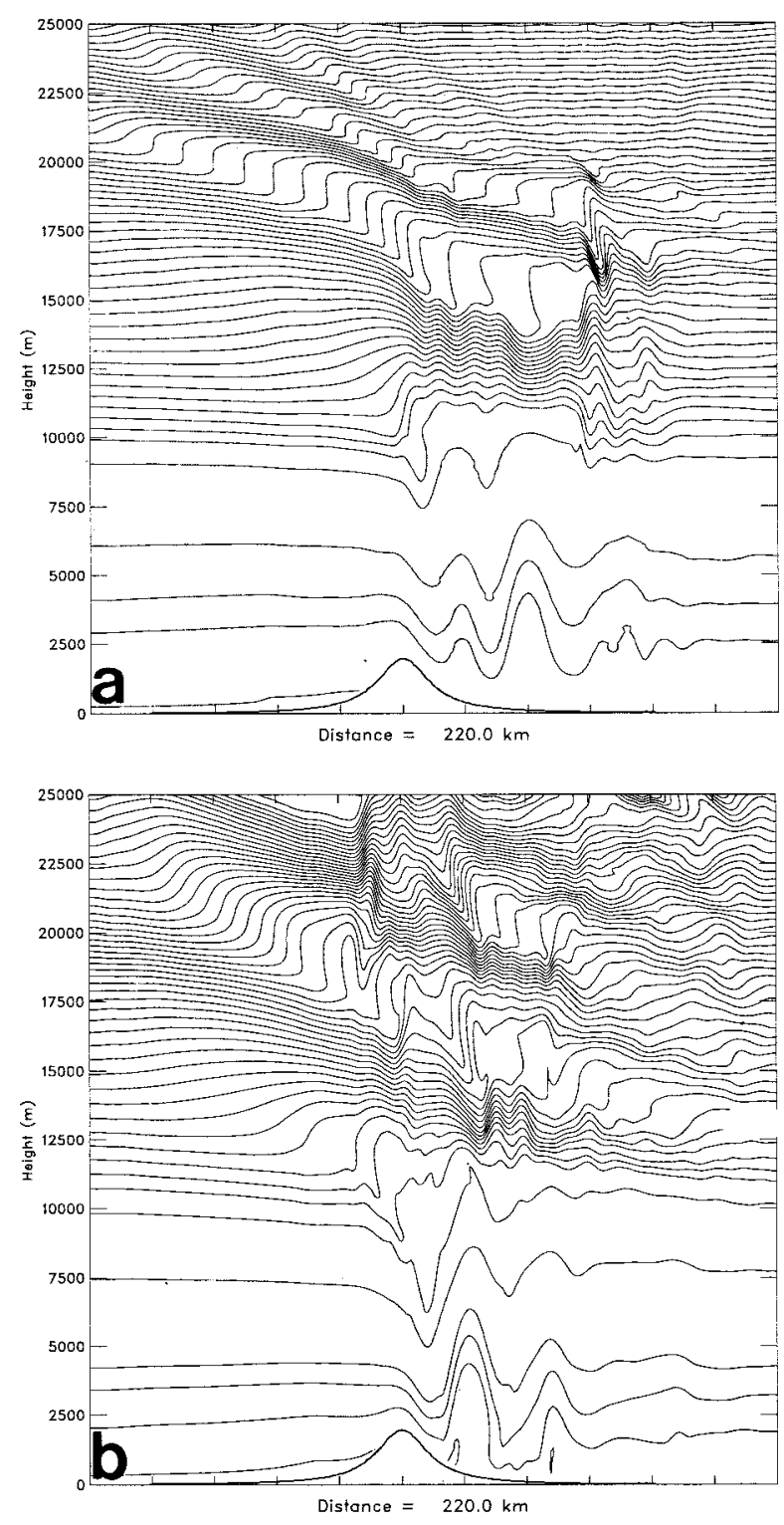

FIG. 8. The 3-h potential temperature for COAMPS initialized using (a) smoothed wind and stratification profiles in the stratosphere (dotted lines in Figs. 1a,b) and (b) uniform stratospheric conditions (Figs. $1 \mathrm{c}, \mathrm{d})$. The contour interval is $8 \mathrm{~K}$.

dictability of wave-breaking events through inadequate specification of the upstream initial conditions.

The initial conditions for the second sensitivity experiment make use of uniform winds and stratification in the stratosphere, which effectively removes the mean state critical level near $21 \mathrm{~km}$ and is similar to the velocity profile applied in the previous simulations of the 1972 Boulder windstorm (e.g., see Figs. 1c,d). The simulated potential temperature using COAMPS after $3 \mathrm{~h}$ is shown in Fig. 8b. Although some general similarities exist between this simulation and the control case (Fig. $3 b)$ with regard to characteristics of the downslope windstorm and low-level hydraulic jump, some striking 

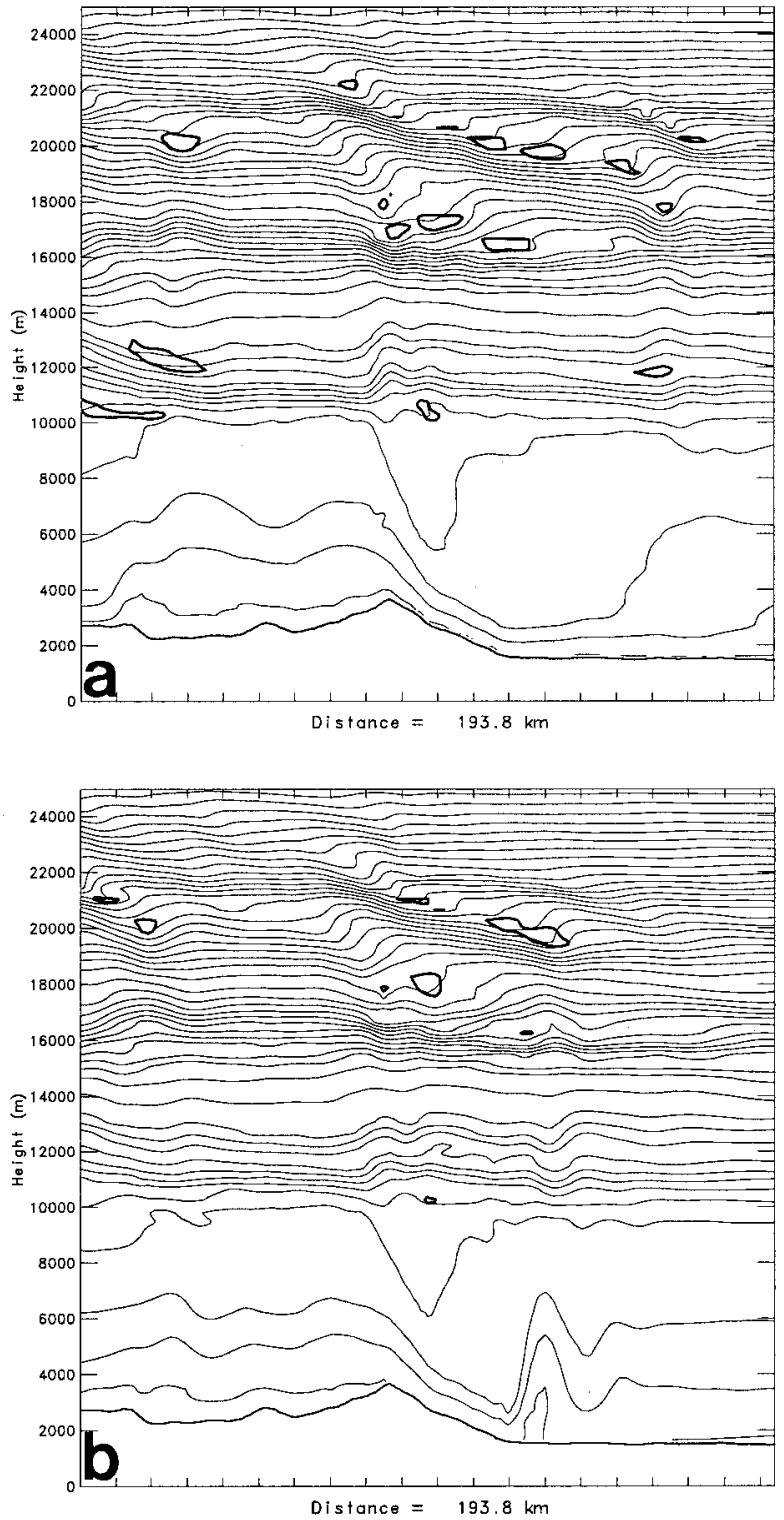

FIG. 9. West-east oriented vertical cross section of potential temperature after $3 \mathrm{~h}$ for a three-dimensional simulation with (a) freeslip bottom boundary condition and (b) surface friction. The contour interval is $8 \mathrm{~K}$. The heavy solid lines represent the 1.0 Richardson number contour in the stratosphere.

differences are apparent. Most notably, the wave breaking in the lower stratosphere is more vigorous than in the control experiment, especially in the layer above 18 $\mathrm{km}$. The presence of the critical layer in the control simulation clearly limits the vertical propagation of gravity waves and ultimately acts as an upper bound on wave breaking. Once again, the local properties of the stratospheric wave breaking are sensitive to the upstream conditions. Additionally, the windstorm is $\sim 10$ $\mathrm{m} \mathrm{s}^{-1}$ weaker using the smoothed stratospheric initial state of Figs. 1c,d relative to the model solution that uses the Grand Junction sounding.

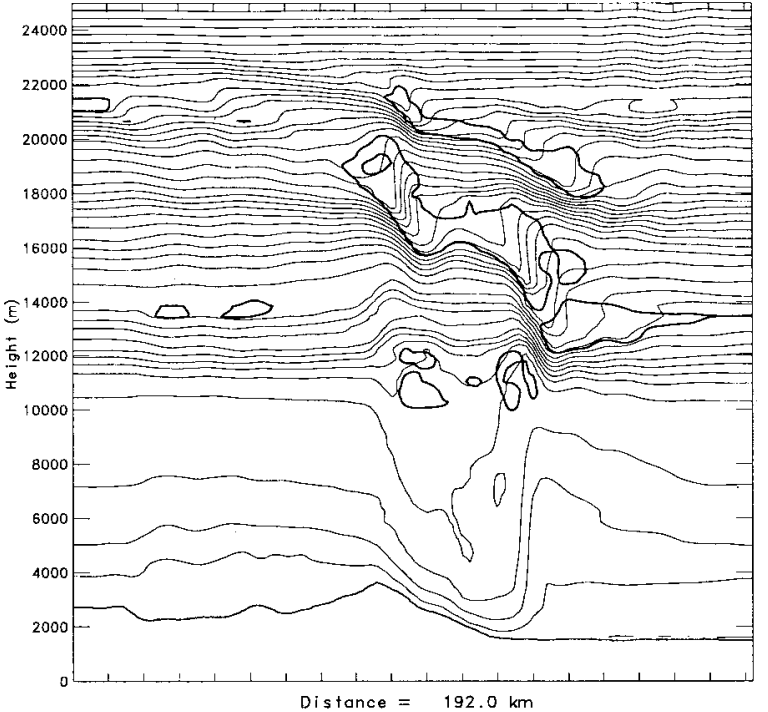

FIG. 10. Vertical cross section of potential temperature after $3 \mathrm{~h}$ for a two-dimensional simulation with free-slip bottom boundary condition and topography representative of a transect across the Continental Divide and Front Range. The contour interval is $8 \mathrm{~K}$. The heavy solid lines represent the 1.0 Richardson number contour in the stratosphere.

Several simulations in three-spatial dimensions were performed using COAMPS to better understand the relationship between the two-dimensional simulations of wave breaking described above and wave breaking in nature. In three-dimensions, the flow is able to split around or pass over the topography, in contrast to twodimensional flow that is either blocked or is forced over the obstacle (e.g., Peng et al. 1995). Clark and Farley (1984) compared two- and three-dimensional simulations of the 1972 Boulder windstorm using a two-dimensional topographic ridge. They compared the surface wave drag in the two simulations and found smaller values for the three-dimensional solution. In three spatial dimensions, turbulent eddies developed in the convectively unstable region of the breaking wave and resulted in a gustiness signature in the surface wind speed. The turbulent energy cascade is not represented properly in two dimensions. It follows that the three-dimensional solution should more accurately capture the turbulent processes and presumably the wave breaking. In the present study, the sensitivity experiments in three spatial dimensions made use of a high-resolution topography dataset. The horizontal grid increment was $2 \mathrm{~km}$ with 75 vertical levels, distributed in a vertically stretched configuration that ranged from $10 \mathrm{~m}$ at the surface to $400 \mathrm{~m}$ in the lower stratosphere. The model was applied without moist processes and rotation. The Grand Junction, Colorado, sounding described above and applied in the two-dimensional simulations was used to initialize the model. A vertical cross section of potential temperature constructed across the continental divide for the 3-h simulation time is shown in Fig. 9a. The wave 
breaking is considerably reduced in amplitude relative to the inviscid, two-dimensional results with topography representative of a transect across the Continental $\mathrm{Di}$ vide and Front Range (cross section topography of Fig. 9), shown in Fig. 10. The vertical wavelength and vertical position of the overturning regions are qualitatively similar. The regions in the stratosphere characterized by $R_{i}$ less than unity are diminished in the three-dimensional simulation as well. The three-dimensionality acts to decrease the overall upper-level wave-breaking activity. The wave breaking is further diminished in the presence of surface friction in agreement with the results of Richard et al. (1989) and Olafsson and Bougeault (1997), as illustrated by the vertical cross section of the three-dimensional simulation with surface friction included shown in Fig. 9b. Surface friction diminishes the shooting flow in the lee and restricts the hydraulic jump movement resulting in a position closer to the mountain, which is in agreement with the aircraft observations (Fig. 2). The wind speed is reduced in a shallow layer above the surface and subsequently results in damping the gravity wave-breaking response.

\section{Summary and conclusions}

A series of modeling experiments have been conducted as part of the pre-MAP research effort. Eleven nonhydrostatic mesoscale models were used in a twodimensional mode to simulate the 11 January 1972 Boulder windstorm event. The model configuration was standardized as much as possible with a horizontal grid increment of $1 \mathrm{~km}$ and a constant vertical grid spacing of $200 \mathrm{~m}$. The initial conditions, which were based on the upstream sounding obtained from Grand Junction, Colorado, contained a critical level near $21 \mathrm{~km}$. The complete upstream sounding was retained in these experiments, which presumably enabled for a more realistic simulation of the stratospheric gravity wave breaking. It follows that the simulations using this sounding represent an opportunity for a fresh perspective on the 1972 Boulder windstorm event. Simulation of this case is ideal for testing and evaluation of mesoscale numerical model codes and numerical algorithms because of the complex wave-breaking response and relative insensitivity to the upper-boundary condition.

The results from the simulations are very encouraging with regard to gravity wave-breaking predictability in that all models produced upper-level wave breaking in similar horizontal locations and vertical layers. The upper-level wave breaking was most pronounced in the 13-16 km and 18-20 km layer with an upstream tilt with height. The wave breaking extended horizontally downstream by $\sim 80-100 \mathrm{~km}$ and $\sim 20 \mathrm{~km}$ upstream. All of the numerical model simulations contained strong leeside winds in the low-levels with a well-defined hydraulic jump, in agreement with the observations of Lilly and Zipser (1972), Klemp and Lilly (1975), and Lilly (1978). However, significant differences among the simulations were apparent in the movement of the hydraulic jump and the depth of the breaking layers. The low-level wind speed and vertical velocity maxima in the lee varied by a factor of 2 among the simulations at specific integration times. However, in some circumstances a comparison of global maxima and minima among models may be difficult to interpret in the presence of high-frequency transients.

Sensitivity experiments indicate that the structure of the wave breaking was impacted by the numerical dissipation, numerical representation of the horizontal advection, and the lateral boundary conditions. The upperlevel wave breaking was found to be particularly sensitive to the vertical resolution, implying that the vertical grid spacing typically used in operational models is likely insufficient to resolve most upper-level gravity wave propagation and breaking processes. Substantial differences exist in the simulation of the wave breaking between one of the models, which did not parameterize the subgridscale eddy viscosity, and the others models, which made use of turbulence parameterization schemes. The simulations of upper-level wave breaking were sensitive to the upper-level upstream conditions. Variations in the vertical shear and stability above 10 $\mathrm{km}$ contributed to significant changes in the structures associated with wave breaking. Additionally, three-dimensionality and surface friction act to decrease the amplitude of the upper-level breaking.

The results from multimodel simulations suggest that the turbulent breakdown of orographically generated gravity wave episodes may be predictable in some circumstances. Wave breaking is generally thought to be a highly nonlinear phenomenon (e.g., Peltier and Clark 1979) and a challenge for numerical models to accurately simulate. However, the coherent transients and longer-temporal scale structures within the gravity wave breakdown regions are surprisingly predictable as evinced by the similarities among the numerical simulations. The results from this test case are based on a group of two-dimensional highly idealized models. The particular case chosen is well suited to two-dimensional idealization. Three-dimensional wave breaking in the presence of temporally varying complex forcing is a significantly more complicated environment to evaluate wave-breaking predictability. Three-dimensional test cases are currently being performed that incorporate complex topographical forcing such as the Alps, as well as real-data initial states, moist dynamics, and rotation. With these numerical experiments performed in conjunction with the MAP research effort, confidence may be established in the capability of sophisticated nonhydrostatic models to predict episodes of the turbulent breakdown of topographically generated gravity waves. These models will serve to guide research missions to observe wave breaking during the field phase of MAP and will serve as dynamical tools to increase our rudimentary understanding of gravity wave dynamics over three-dimensional complex topography. 
Acknowledgments. J. D. Doyle was supported by the Office of Naval Research's Program Element $0601153 \mathrm{~N}$, with computing time supported in part by a grant of HPC time from the Department of Defense Shared Resource Center, Stennis Space Center, Mississippi, and performed on a Cray T-90. D. R. Durran's research was supported by NSF Grant ATM-9530662. G. S. Poulos was supported by NSF Grant ATM9713073. Support for M. Xue was obtained through NSF Grant ATM91-20009 to the Center for Analysis and Prediction of Storms (CAPS). The research of D. Landau and M. G. Wurtele was sponsored in part under Grant NCC2-374 from NASA Dryden Flight Research Center to UCLA Center for Flight Systems Research. The National Center for Atmospheric Research is sponsored by the National Science Foundation. Use of the 2D version of the MM5 was made possible by the Microscale and Mesoscale Meteorological Division of the National Center for Atmospheric Research (NCAR), which is supported by the National Science Foundation. The research of D. Landau and M. G. Wurtele benefited from discussions with L. J. Ehrenburger.

\section{REFERENCES}

Aebischer, U., and C. Schär, 1998: Low-level potential vorticity and cyclogenesis to the lee of the Alps. J. Atmos. Sci., 55, 186-207.

Asselin, R., 1972: Frequency filter for time integrations. Mon. Wea. Rev., 100, 487-490.

Bacmeister, J. T., and M. R. Schoeberl, 1989: Breakdown of vertically propagating two-dimensional gravity waves forced by orography. J. Atmos. Sci., 46, 2109-2134.

Binder, P., and C. Schär, Eds., 1996: Mesoscale Alpine Programme (MAP): Design Proposal. 2d ed. MAP Publications, $77 \mathrm{pp}$.

Blumen, W., 1988: The effects of a periodic upstream flow on nonlinear hydrostatic mountain waves. J. Atmos. Sci., 45, 34603469.

Bretherton, F. P., 1969: Momentum transport by gravity waves. Quart. J. Roy. Meteor. Soc., 95, 213-243.

Brinkman, W. A. R., 1974: Strong downslope winds at Boulder. Mon. Wea. Rev., 102, 592-602.

Chen, C., 1991: A nested grid, nonhydrostatic, elastic model, using a terrain-following coordinate transformation-The radiative nesting boundary conditions. Mon. Wea. Rev., 119, 2852-2869.

Clark, T. L., and W. R. Peltier, 1977: On the evolution and stability of finite amplitude mountain waves. J. Atmos. Sci., 34, 17151730.

— lations in two and three spatial dimensions using anelastic interactive grid nesting: A possible mechanism for gustiness. $J$. Atmos. Sci., 41, 329-350.

Dörnbrack, A., and T. Dürbeck, 1998: Turbulent dispersion of aircraft exhausts in regions of breaking gravity waves. Atmos. Environ., 32, 3105-3112.

Dudhia, J., 1993: A nonhydrostatic version of the Penn State-NCAR mesoscale model: Validation tests and simulation of an Atlantic Cyclone and Cold Front. Mon. Wea. Rev., 121, 1493-1513.

Durran, D. R., 1986: Another look at downslope windstorms. Part I: The development of analogs to supercritical flow in an infinitely deep, continuously stratified fluid. J. Atmos. Sci., 43, 2527-2543. , and J. B. Klemp, 1983: A compressible model for the simulation of moist mountain waves. Mon. Wea. Rev., 111, 2341-2361.

Hodur, R. M., 1997: The Naval Research Laboratory's Coupled Ocean/Atmosphere Mesoscale Prediction System (COAMPS). Mon. Wea. Rev., 125, 1414-1430.

Houze, R., J. Kuettner, and R. Smith, Eds., 1998: Mesoscale Alpine Programme (MAP) U.S. Overview Document and Experiment
Design. 69 pp. [Available from U.S. MAP Programme Office, UCAR, JOSS, P.O. Box 3000, Boulder, CO 80307-3000.]

Huang, C.-Y., 2000: A forward-in-time anelastic nonhydrostatic model in a terrain-following coordinate. Mon. Wea. Rev., in press.

Klemp, J. B., and D. K. Lilly, 1975: The dynamics of wave-induced downslope winds. J. Atmos. Sci., 32, 320-339.

— waves. J. Atmos. Sci., 35, 78-107.

Lafore, J. P., and Coauthors, 1998: The Meso-NH atmospheric simulation system. Part I: Adiabatic formulation and control simulations. Ann. Geophys., 16, 90-109.

Landau, D. M., L. J. Ehernberger, M. J. Wurtele, and R. M. Turco, 1997: Linking mountain wave rotor development to terrain geometry and vegetative roughness. Preprints, Seventh Conf. on Aviation, Range, and Aerospace Meteorology, Long Beach, CA, Amer. Meteor. Soc., 218-223.

Lilly, D. K., 1978: A severe downslope windstorm and aircraft turbulence event induced by a mountain wave. J. Atmos. Sci., 35, 59-77.

—_ and E. J. Zipser, 1972: The Front Range windstorm of January 11 1972. Weatherwise, 25, 56-63.

Lott, F., 1995: Comparison between the orographic response of the ECMWF model and the PYREX 1990 data. Quart. J. Roy. Meteor. Soc., 121, 1323-1348.

Nastron, G. D., and D. C. Fritts, 1992: Sources of mesoscale variability of gravity waves. Part I: Topographic excitation. J. Atmos. Sci., 49, 101-110.

Olaffson, H., and P. Bougeault, 1997: Why was there no wave breaking in PYREX? Beitr. Phys. Atmos., 70, 167-170.

Palmer, T. N., G. J. Shutts, and R. Swinbank, 1986: Alleviation of systematic westerly bias in general circulation and numerical weather prediction models through an orographic gravity wave drag parameterization. Quart. J. Roy. Meteor. Soc., 112, 10011039 .

Peltier, W. R., and T. L. Clark, 1979: The evolution and stability of finite-amplitude mountain waves. Part II: Surface wave drag and severe downslope windstorms. J. Atmos. Sci., 36, 1498-1529.

- , and - 1983: Nonlinear mountain waves in two and three spatial dimensions. Quart. J. Roy. Meteor. Soc., 109, 527-548.

Peng, M. S., S.-W. Li, S. W. Chang, and R. T. Williams, 1995: Flow over mountains: Coriolis force, transient troughs and three dimensionality. Quart. J. Roy. Meteor. Soc., 121, 593-613.

Pielke, R. A., and Coauthors, 1992: A comprehensive meteorological modeling system-RAMS. Meteor. Atmos. Phys., 49, 69-91.

Ralph, F. M., P. J. Neiman, and D. Levinson, 1997: Lidar observations of a breaking mountain wave associated with extreme turbulence. Geophys. Res. Lett., 24, 663-666.

Robert, A. J., 1966: The investigation of a low order spectral form of the primitive meteorological equations. J. Meteor. Soc. Japan, 44, 237-245.

Richard, E., P. Mascart, and E. C. Nickerson, 1989: The role of surface friction in downslope wind storms. J. Appl. Meteor., 28, 241251.

Queney, P., G. A. Corby, N. Gerbier, H. Koschmieder, and J. Zierep, 1960: The airflow over mountains. WMO Tech. Note No. 34, 135 pp.

Schär, C., and R. B. Smith, 1993: Shallow-water flow past isolated topography. Part I: Vorticity production and wake formation. $J$. Atmos. Sci., 50, 1373-1400.

— in continuously stratified flows past isolated topography. J. Atmos. Sci., 54, 534-554.

Smith, R. B., 1979: The influence of mountains on the atmosphere. Advances in Geophysics, Vol. 21, Academic Press, 87-230.

— , and S. Grønås, 1993: Stagnation points and bifurcation in 3D mountain airflow. Tellus, 45A, 28-43.

Smolarkiewicz, P. K., and L. G. Margolin, 1997: On forward-in-time differencing for fluids: An Eulerian/semi-Lagrangian non-hydrostatic model for stratified flows. Atmos.-Ocean, 35, 127-152.

Thorpe, A. J., H. Volkert, and D. Heimann, 1993: Potential vorticity of flow along the Alps. J. Atmos. Sci., 50, 1573-1590.

Xue, M., K. K. Droegemeier, V. Wong, A. Shapiro, and K. Brewster, 1995: ARPS version 4.0 user's guide. Center for Analysis and Prediction of Storms. [Available from CAPS, University of Oklahoma, 100 E. Boyd St., Norman, OK 73019.] 